\title{
Sabit Zaman Gecikmeli Tek Serbestlik Dereceli Bir Haptik-Teleoperasyon Sisteminin Kontrolü
}

\author{
Tayfun ABUT ${ }^{1^{*}}$, Servet SOYGÜDER ${ }^{2}$ \\ ${ }^{1}$ Makine Mühendisliği, Mühendislik-Mimarlık Fakültesi, Muş Alparslan Üniversitesi, Muş, Türkiye \\ ${ }^{2}$ Endüstri Mühendisliği, Mühendislik ve Doğa Bilimleri Fakültesi, Ankara Yıldırm Beyazıt Üniversitesi, Ankara, Türkiye \\ ${ }^{* 1}$ tayfunabut@gmail.com, ${ }^{2}$ servetsoyguder@gmail.com
}

Öz: Haptik-teleoperasyon sistemlerinin performansının arttırılması amacıyla çeşitli çalışmalar yürütülmektedir. Haptikteleoperasyon sistemlerinde iki temel unsur hedeflenmektedir. Birinci kararlılık(stability) ikincisi ise şeffaflık(transparency)'tır. Özellikle kararlılığı, şeffaflığı bozan ve performansı etkileyen en önemli problemlerden biri zaman gecikmesidir. Zaman gecikmesi haptik teleoperasyon sistemlerinin performansını oldukça kötü etkilemektedir. Bu çalışmada tek serbestlik dereceli robotlardan oluşan haptik-teleoperasyon sisteminin sabit zaman gecikmeli kontrolü hedeflenmiştir. Öncelikle sistemi oluşturan robotların hareket denklemleri elde edilmiştir. Dalga değişken yöntemi(Wave Variables Method) kullanılarak sabit zaman gecikmesi telafi edilmiştir.200,400 ve 800 milisaniye zaman gecikmesinin varlığında sistem kontrol edilmiştir. Elde edilen sonuçlar iki farklı performans kriterleri (MAE ve MSE) kullanılarak elde edilmiş ve tablolar şeklinde verilmiştir. Sonuçlar grafikler ve tablolar şeklinde verilmiş ve irdelenmiştir.

Anahtar kelimeler: Haptik-Teleoperasyon, Tek Serbestlik Dereceli Robot, Sabit Zaman Gecikmesi, Dalga Değişken Yöntemi

\section{Control of a Single Degree of Freedom Haptic-Teleoperation System with Constant Time Delay}

\begin{abstract}
Various studies are carried out to increase the performance of haptic-teleoperation systems. Two main elements are targeted in haptic-teleoperation systems. The first is stability, and the second is transparency. Especially one of the most important problems that affect stability, transparency, and affect performance is the time delay. Time delay affects the performance of haptic teleoperation systems very badly. In this study, it is aimed to control the haptic-teleoperation system consisting of single degree of freedom robots with constant time delay. First of all, the motion equations of the system were obtained. A constant time delay was compensated by using the Wave Variables Method. The system has been checked in the presence of 200, 400, and 800 millisecond time delay. The results obtained were obtained using two different performance criteria (MAE and MSE) and have been presented in tables. The results have been given in the form of graphs and tables and were examined.
\end{abstract}

Key words: Haptic-Teleoperation, Single Degree of Freedom Robot, Constant Time Delay, Wave Variable Method

\section{Giriş}

Haptik-teleoperasyon sistemleri kullanım alanlarının geniş bir yelpazede olmasından ötürü birçok alanda aktif olarak araştırılmaktadır. Bunlardan bazıları savunma endüstrisinden, robotik cerrahiye ve simülatörlere vb. alanlarıdır [1-5]. Teleoperasyon çalışmalarında iletişim kanalında meydana gelen zaman gecikmesi sistemin kontrolünde büyük problemlere neden olmaktadır. Çünkü bu zaman gecikmesi sistemi kararsız ve kontrol edilemeyecek bir hale getirmektedirler. Literatürde bu problemi çözmek için çeşitli yöntemler önerilmiş ve uygulanmıştır. Ferrel tek serbestlik dereceli sistemde zaman gecikmesinin düşük miktarının bile sistemde kararsızlığa yol açtığını göstermiş ve bu durumlarda da görevin tamamlanması için yeterince kararlı kalması gerektiği sonucuna varmıştır [6]. Zaman gecikmesi problemi haptik-teleoperasyon sistemlerini kararsız bir duruma getirmektedir. Bu konuda Anderson ve Spong tarafından yapılan çalışmada iletişim kanalının pasif(passivity) olmayan yapısından dolayı kararsızlaştığı sonucuna varılmıştır. Ayrıca yaptıkları çalışmada pasiflik tabanlı Scattering dönüşümünü sabit zaman gecikmeleri için önermişlerdir[7]. Niemeyer ve Slotine, Scattering dönüşümünü geliştirerek dalga değişken yöntemini önermiştir. Niemeyer ve Slotine, iletişim kanalının giriş ve çıkışlarına yeni değişkenler tanımlamıştır. Hız ve kuvvet gibi geleneksel güç değişkenleri yerine dalga değişkenleri önermiştir. Hız ve kuvvet sinyallerine iletişim kanalı öncesinde bu dalga değişkenleri dönüşümü uygulanarak sinyaller dalga değişkenlerine dönüştürülmüştür. Scattering teorisindeki sonucun aynısına dalga teorisiyle de

\footnotetext{
* Sorumlu yazar: tayfunabut@gmail.com. Yazarların ORCID Numarası: ${ }^{1}$ 0000-0003-4646-3345, ${ }^{2}$ 0000-0002-8191-6891
} 
ulaşılmıştır[8]. Munir ve Book pozisyon sapması problemi için kalman filtresi tabanlı bir yöntem üzerine çalışmıştır[9]. Dalga değişken yöntemi yaklaşımı kullanılarak pozisyon sapması problemini azaltmak için Chopra ve diğerleri klasik dalga değişkenine bir döngü eklemişlerdir[10]. Hirche ve diğerleri iki yönlü zaman gecikmesi probleminin çözümünde en başarılı yöntemlerden biri olduğunu ifade etmişlerdir[11]. Diolaiti ve diğerleri dalga değişken yöntemini kullanarak daha fazla rijitlik elde etmek için motor akımı ve voltajıyla doğrudan etkileşime girmişlerdir [12].Veri kaybı ve değişken zaman gecikme varlığında Rodriguez-Seda ve diğerleri dalga tabanlı pasifliği sağlamak için sönüm ekleme tipinde ve pozisyon hatalarının da göz önüne alındığı bir yaklaşımla deneysel bir çalışma gerçekleştirmiştir[13]. Benedetti ve diğerleri empedans eşleştirme yaklaşımında karalı durum hatası olmasına rağmen geçici salınımları yok etmek için bir çalışma gerçekleştirmişlerdir[14]. Aziminejad ve diğerleri ana ve bağımlı robot taraflarında kuvvet sensörü kullanılmasının şeffaflığı önemi ölçüde arttırdığını göstermiştir[15]. Bate ve diğerleri geriye doğru hız bilgisini kaldırarak dalga yansımalarını azaltmak için bir çalışma yapmışlardır[16]. Zaman gecikmesi varlığında telerobotik sistemler için dalga değişken yöntemine gerisürülebilirliği üzerine deneysel çalışma ile etkileri Li ve Kawashima tarafından araştırılmıştır[17]. Soyguder ve Abut yaptıkları çalışmada değişken zaman gecikmesi varlığında modifiye edilmiş dalga değişken yöntemini kullanarak kararlı bir pozisyon performansı elde etmek için bir kontrol yöntemi önermiştir[18]. Zaman gecikmeleri altında dört kanallı doğrusal olmayan iki taraflı teleoperasyon sisteminin pasiflik ve dalga değişken tabanlı kontrol gerçekleştirilmiştir[19]. Dinamik belirsizlikleri ve zaman gecikmelerinin etkisini azaltmak için dalga değiş̧kenli radyal tabanlı sinir ağları (RBFNN) kontrol yöntemi kullanılmıştır[20].Birçok araştırmacı tarafından dalga değişken yöntemi araştırılmış, geliştirilmiş ve geliştirilmeye devam ettirilmektedir[21-23]. Şekil 1'de iki yönlü teleoperasyon sisteminin genel görünümü gösterilmiştir.

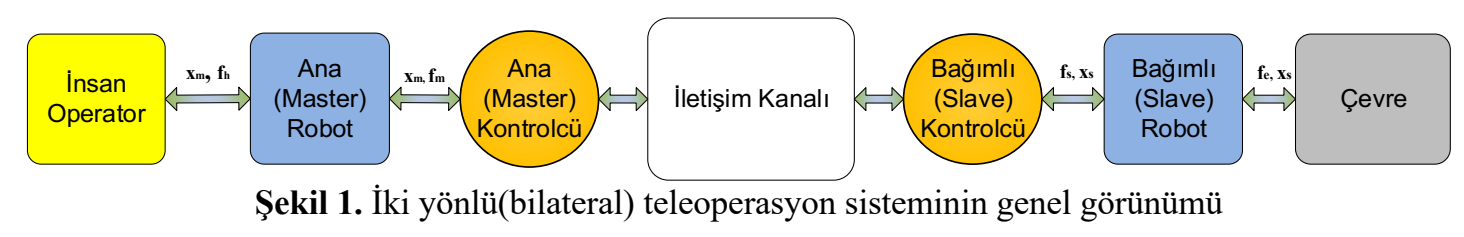

Bu çalışmada haptik-teleoperasyon sistemlerinin kararlılığı, şeffaflığı bozan ve performansı etkileyen en önemli problemlerden biri zaman gecikmesi problemi giderilmeye çalışılmıştır. Tek serbestlik dereceli robotlardan oluşan haptik-teleoperasyon sisteminin sabit zaman gecikmesi varlığında kontrolü hedeflenmiştir. Öncelikle sistemi oluşturan robotların hareket denklemleri elde edilmiştir. Dalga değişken yöntemi(Wave Variables Method) kullanılarak sabit zaman gecikmesi telafi edilmiştir.200,400 ve 800 milisaniye zaman gecikmesinin varlığında sistem kontrol edilmiştir. Elde edilen sonuçlar iki farklı performans kriteri(MAE ve MSE) kullanılarak değerlendirilmiştir. Sonuçlar grafikler ve tablolar şeklinde verilmiştir ve irdelenmiştir.

\section{Sistemin Modellenmesi}

Haptik-teleoperasyon sisteminin hareket denklemleri Lagrange-Euler yöntemi ile elde edilmiştir. Sistemi oluşturan robotlar tek serbestlik derecesine sahiptir. Ana (master) ve bağımlı (slave) robotlardan oluşan sistemin hareket denklemleri 1 ve 2 nolu denklemlerde verilmiştir.

$I_{m} \ddot{q}_{m}+b_{m} \dot{q}_{m}=f_{h}+\tau_{m}$

$I_{s} \ddot{q}_{s}+b_{s} \dot{q}_{s}=\tau_{s}-f_{e}$

Konum, hız, ivme ve tork ifadeleri sırasıyla $\ddot{q}_{i}, \dot{q}_{i}, q_{i}$ ve $\tau_{i}$ gösterilmiştir. Ana ve bağımlı robotları $i \in$ $\{m, s\}$ indisleri göstermektedir. Sisteme ait atalet momentleri $I_{m}$ ve $I_{s}$, sönüm katsayılarını $b_{m}$ ve $b_{s}$ göstermektedir. Ana ve bağımlı robotların tork ifadelerini $\tau_{m}$ ve $\tau_{s}$ göstermektedir. Kullanıcı tarafından uygulanan ve çevreden sisteme etki eden bozucu tork ifadelerini $\tau_{h}$ ve $\tau_{e}$ göstermektedir. Ana ve bağımlı robotların çevre ile etkileşim modelleri yay-damper şeklinde modellenmiştir.

$$
\begin{aligned}
& \tau_{h}=J_{m}{ }^{T} f_{h}, \tau_{e}=J_{s}{ }^{T} f_{e} \\
& f_{h}=k_{h} \Delta_{h}+b_{h} \dot{\Delta}_{h}, \Delta_{h}=z_{m}-z_{s}
\end{aligned}
$$


$f_{e}=k_{e} \Delta_{e}+b_{e} \dot{\Delta}_{e}, \Delta_{e}=z_{r}-z$

Yukarıda verilen denklemlerden $f_{e}$ ve $f_{s}$ temas sırasında meydana gelen insan ve çevre kuvvetlerini göstermektedir. Yay sabitleri $k_{h}$ ve $k_{e}$, sönüm katsayılarını $b_{h}$ ve $b_{e}$ göstermektedir. Sistemi oluşturan robotlardan bir tanesinin modeli Şekil 2'de verilmiştir.

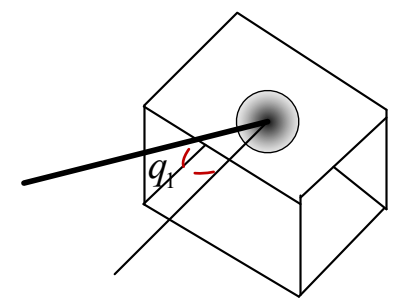

Şekil 2. Sistemi oluşturan robotlardan bir tanesinin modeli

\section{Dalga Değişkenleri Yöntemi(Wave-Variables Method)}

Dalga değişkenleri (wave variables) yöntemi, Scattering teorisi geliştirilerek bulunmuştur[8]. Niemeyer ve Slotine, iletişim kanalının giriş ve çıkışlarına yeni değişkenler tanımlamışlardır. Hız ve kuvvet gibi geleneksel güç değişkenleri yerine dalga değişkenleri önermişlerdir. Hiz ve kuvvet sinyallerine iletişim kanalı öncesinde bu dalga değişkenleri dönüşümü uygulanarak sinyaller dalga değişkenlerine dönüştürülmüştür. Standart sabit zaman gecikmeli Scattering dönüşümüne ait blok diyagramı Şekil 3'te verilmiştir.

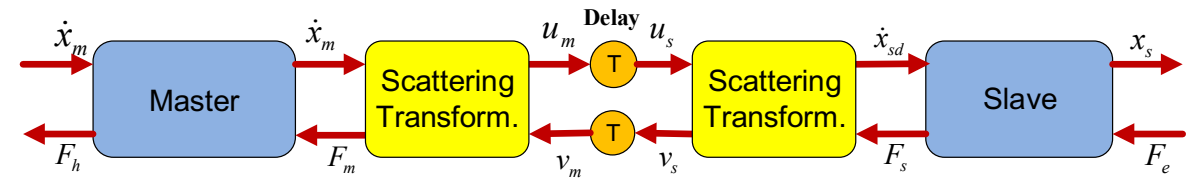

Şekil 3. Standart sabit zaman gecikmeli Scattering dönüşümü

İletişim kanalının her iki tarafındaki giriş ve çıkışları güç akışına dalga değişkenleri uygulanarak giriş ve çıkış dalgaları olarak adlandırılmaktadır. Güç sinyalleri olan hız ve kuvvet sinyalleri dalga değişkenlerine dönüştürülmektedir. Standart güç değişkenlerinden aşağıdaki dönüşümlerle dalga değişkenleri elde edilmektedir.

$u_{m}=\frac{1}{\sqrt{2 b}}\left(b \dot{x}_{m}+F_{m}\right) ; u_{s}=\frac{1}{\sqrt{2 b}}\left(b \dot{x}_{s}+F_{s}\right)$

$v_{m}=\frac{1}{\sqrt{2 b}}\left(b \dot{x}_{m}-F_{m}\right) ; v_{s}=\frac{1}{\sqrt{2 b}}\left(b \dot{x}_{s}-F_{s}\right)$

Dalga empedansı olarak adlandırılan $b$ pozitif sabit bir sayıyı veya simetrik olan bir pozitif matrisi göstermektedir. Ana ve bağımlı robotların hızları $\dot{x}_{m}$ ve $\dot{x}_{s}$, ana ve bağımlı robotların kuvvetleri $F_{m}$ ve $F_{s}$, insan operator ve etkileşim sonucu elde edilen kuvvet $F_{h}$ ve $F_{e}$ ile gösterilmiştir. Dalga değişkenleri $u$ ve $v$ gösterilmektedir. Bir sistemin pasiflik(passivity) tabanında bakılması için öncelikle sistemin gücünü formüle edilmesi gerekmektedir. Güç $\left(P_{\text {in }}\right)$, sisteme giren $(x)$ ve çıkan $(y)$ vektörlerin skaler çarpımı şeklinde formüle edilmiştir. Bu formülü sağlayan tüm sistemler pasiftir. Sistemdeki güç ya depolanmış ya da harcanmıştır. Aşağıda verilen formüle göre $t$ anına kadar bir sistem tarafindan üretilen toplam enerji ilk depolanan enerjiyle sınırlı olduğu ifade edilebilir, bir başka söylemle enerji dönüşümü negatif ilk enerjiyle sınırlıdır:

$\int_{0}^{t} P_{\text {in }}(t)=\int_{0}^{t} x^{t} y d \tau \geq E_{\text {store }}(t)-E_{\text {store }}(0)$

Zamanla depolanan enerji $E_{\text {store }}(t)$, ilk depolanan enerji ise $E_{\text {store }}(0)$ ile tanımlanmıştır. Sistem çalışırken herhangi bir anda iletişim bloğu içerisinde güç girişi aşağıdaki formülle gösterilmektedir. Dalga değişken dönüşüm blok diyagramı Şekil 4'de verilmiştir.

$P_{\text {in }}(t)=\dot{x}_{m d}(t) F_{m}(t)-\dot{x}_{s d}(t) F_{s}(t)$ 


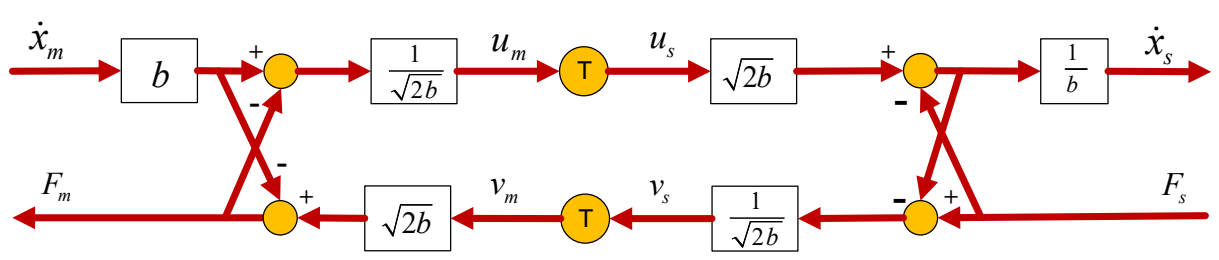

Şekil 4. Dalga değişken dönüşüm yöntemi blok diyagramı

İletişim kanalında $T$ kadar sabit bir zaman gecikmesi maruz kaldığında, gidiş ve dönüşte iletilen sinyaller aşağıdaki gibi elde edilir.

$$
\begin{aligned}
& u_{s}(t)=u_{m d}(t)=u_{m}(t-T) \\
& v_{m}(t)=v_{s d}(t)=v_{s}(t-T)
\end{aligned}
$$

8 nolu denklemin içerisine elde edilen 10 ve 11 nolu denklemler yazıllğında başlangıç enerjisi varsayılarak ana ve bağımlı robotlar arasında iletişim esnasında depolanan toplam enerji miktarı 12 nolu denklem ile elde edilmektedir. 12 nolu denklem incelediğinde kayıpsız ve pasif bir iletişim kanalı elde edilmiştir ve pasiflik özelliğinin zaman gecikmesi miktarından tamamen bağımsız olduğu görülmüştür.

$$
\begin{aligned}
& E=\int_{0}^{t} P_{i n}(\tau) d \tau=\int_{0}^{t}\left(\dot{x}_{m d}(\tau) F_{m}(\tau)-\dot{x}_{s d}(\tau) F_{s}(\tau)\right) d \tau \\
& E=\frac{1}{2} \int_{0}^{t} u_{m}^{T}(\tau) u_{m}(\tau)-v_{m}^{T}(\tau) v_{m}(\tau)+v_{s}^{T}(\tau) v_{s}(\tau)-u_{s}^{T}(\tau) u_{s}(\tau) d \tau \\
& E=\frac{1}{2} \int_{0}^{t}\left(u_{m}^{T}(\tau) u_{m}(\tau)+v_{s}^{T}(\tau) v_{s}(\tau)\right) d \tau \geq 0
\end{aligned}
$$

\section{Sayısal Benzetim (Numerical Simulation) Sonuçları}

Sistemin hareket denklemleri ve dalga değişken yöntemi kullanılarak benzetim çalışmaları yapılmıştır. Konum, hız ve kuvvet kontrol parametreleridir. Tek serbestlik dereceli robotlardan oluşan haptik-teleoperasyon çok serbestlik dereceli robotlar ile gerçekleştirilen çalışmalar için oldukça önemli bir temel oluşturmaktadır. Şekil 5 ' te ana ve bağımlı robottan oluşan haptik-teleoperasyon sisteminin modeli verilmiştir.

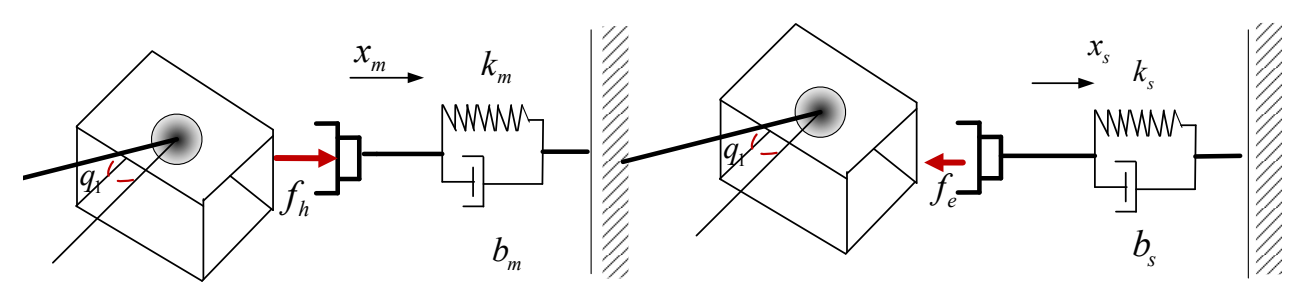

Şekil 5. Ana(master) ve bağımlı(slave) robotların çevre ile etkileşiminin benzetim modeli

Çalışmada ilk aşama olarak sistemin hareket denklemleri elde edilmiştir. İkinci olarak bu denklemler benzetim ortamında çalışır hale getirilmiş̧tir. Sistemde ana robot tarafinda üretilen pozisyon veya hız bilgisinin bağımlı robot tarafından maksimum oranda takip edilmesi, benzer şekilde bağımlı robot tarafından etkileşim sonucu elde edilen kuvvet veya tork bilgilerinin maksimum oranda ana robot tarafinda hissedilmesi hedeflenmiştir. Öncelikle elde edilen denklemler kullanılarak sistemin zaman gecikmesiz bir şekilde kontrolü gerçekleştirilmiştir. Ana ve bağımlı robotların fiziksel parametreleri $m_{m}=m_{s}=0.038 \mathrm{~kg}, l_{m}=l_{s}=0.1525 \mathrm{~m}$ ve $I_{m}=I_{s}=0.01 \mathrm{~kg}-m^{2}$ şeklinde alınmıştır. İnsan ve çevre modellerinin yay katsayıları $k_{h}=k_{e}=10 \mathrm{~N} / \mathrm{m}$ ve sönüm katsayıları $b_{h}$ and $b_{e}=2 \mathrm{Ns} / \mathrm{m}$ 'dir. 
Ayrıca insan ve çevre tork değerleri elde edilirken başlangıç şartı yani $z_{0}=0$ alınmıştır. Ardından sisteme 200 milisaniye(ms) sabit zaman gecikmesi eklenerek Şekil 6'da verilen grafik elde edilmiştir. Grafikte de görüldüğü üzere sistemin pozisyon takibinde performans düşüklüğüne sebep olmaktadır.

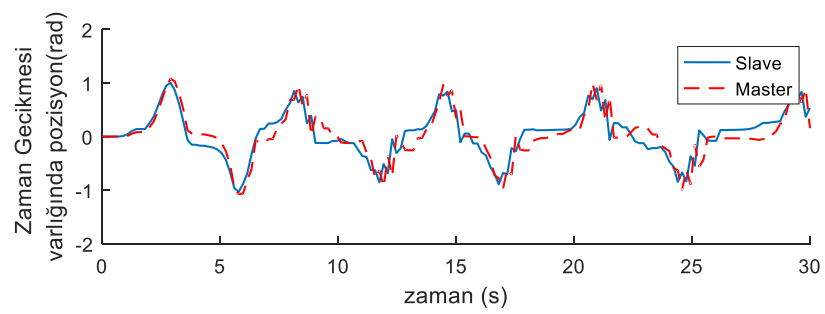

Şekil 6. Zaman gecikmesi varlığında elde edilen robot pozisyon açısı

Sisteme sırasıyla 200,400 ve 800 milisaniye(ms) sabit zaman gecikmeleri eklenmiştir. Sistemin çalı̧̧ma süresi 30 saniye olarak alınmıştır. Ortalama mutlak hata (Mean Absolute Error (MAE)) ve Ortalama karesel hata (Mean Square Error (MSE)) performans kriterleri kullanılarak yöntemin sonuçları tablolar halinde verilmiş ve irdelenmiştir.

$$
\begin{aligned}
& M S E=\frac{1}{N}\left(\sum_{j}^{N} y_{m_{j}}-y_{s_{j}}\right)^{2} \\
& M A E=\frac{1}{N}\left(\sum_{j}^{N}\left|y_{m_{j}}-y_{s_{j}}\right|\right)
\end{aligned}
$$

$y_{m j}$ ana robotun $j$. değeri $y_{s j}$ ise bağımlı robotun $j$. değerini göstermektedir. $y$ ise açı veya tork $(\theta \& \tau)$ ifadesini temsil etmektedir. $j=1,2,3,4 \ldots . N$ 'dir. Ayrıca bu kısımda dalga değişken yönteminin performans değerleri grafiksel olarak verilmiştir. Şekil 7-a'da $200 \mathrm{~ms}$ zaman gecikmesi varlığında ana (master) ve bağımlı (slave) robotların sırasıyla pozisyon, hız ve kuvvet grafikleri, Şekil 7-b'de ise bu parametrelerin hata grafikleri verilmiştir. Şekil 8a'da $400 \mathrm{~ms}$ zaman gecikmesi varlı̆̆ında ana (master) ve bağımlı (slave) robotların sırasıyla pozisyon, hız ve kuvvet grafikleri, Şekil 8-b'de ise bu parametrelerin hata grafikleri verilmiştir. Şekil 9-a'da $800 \mathrm{~ms}$ zaman gecikmesi varlığında ana (master) ve bağımlı (slave) robotların sırasıyla pozisyon, hız ve kuvvet grafikleri, Şekil 9-b'de ise bu parametrelerin hata grafikleri verilmiştir. $200 \mathrm{~ms}$ sabit zaman gecikmesi varlığında elde edilen grafikler gözlemlendiğinde ana robot tarafından gönderilen pozisyon değerinin bağımlı robot tarafına iletildiği ve hata değerinin $+0.02 \sim-0.02$ değerleri arasında değiştiği görülmüsştür. Hız grafiği göz önüne alındığında ise hızın pozisyon grafiğine göre biraz daha düşük miktarda iletildiği ve hata değerlerinin $+0.5 \sim-0.5$ değerleri arasında değiştĭgi görülmüştür. Tork grafiği incelendiğinde zaman gecikmesinin bağımlı robot tarafinda üretilen tork bilgisinin iletilmesini olumsuz yönde etkilediği yaklaşık 8 saniye civarından sonra bir miktar sapma meydana geldiği görülmüştür. $+0.5 \sim-0.5$ aralığında hata değerlerinin değiştiği görülmüştür.
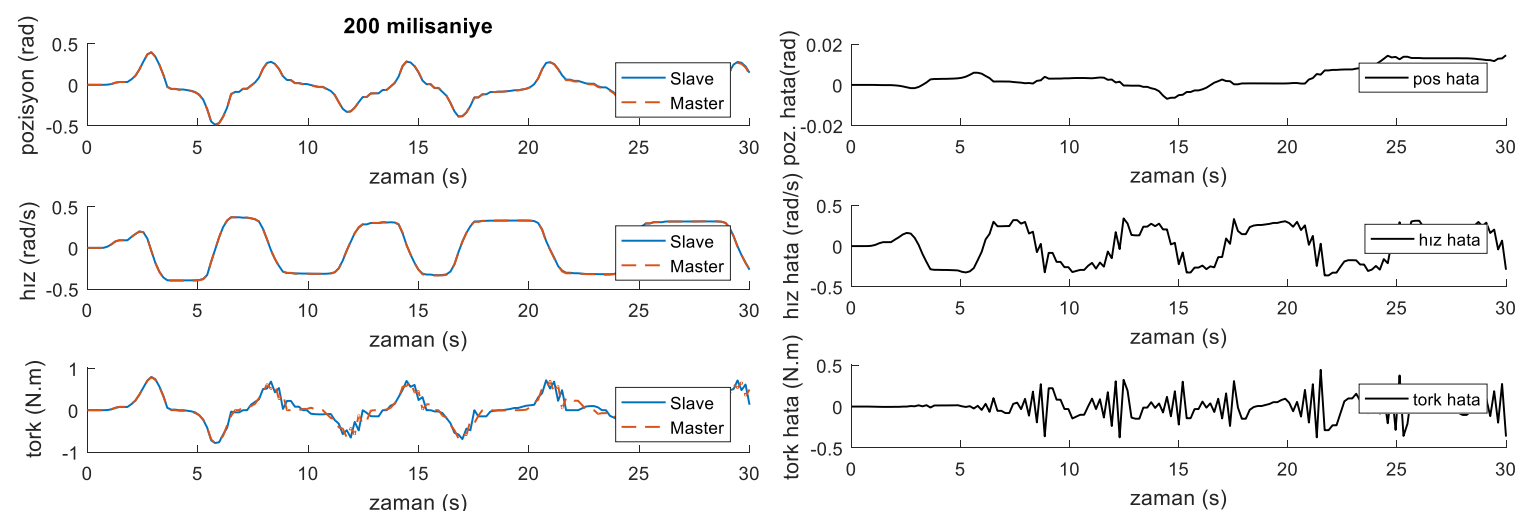

a

b

Şekil 7. 200 ms zaman gecikmesi varlığında elde edilen robot eklem açısı 

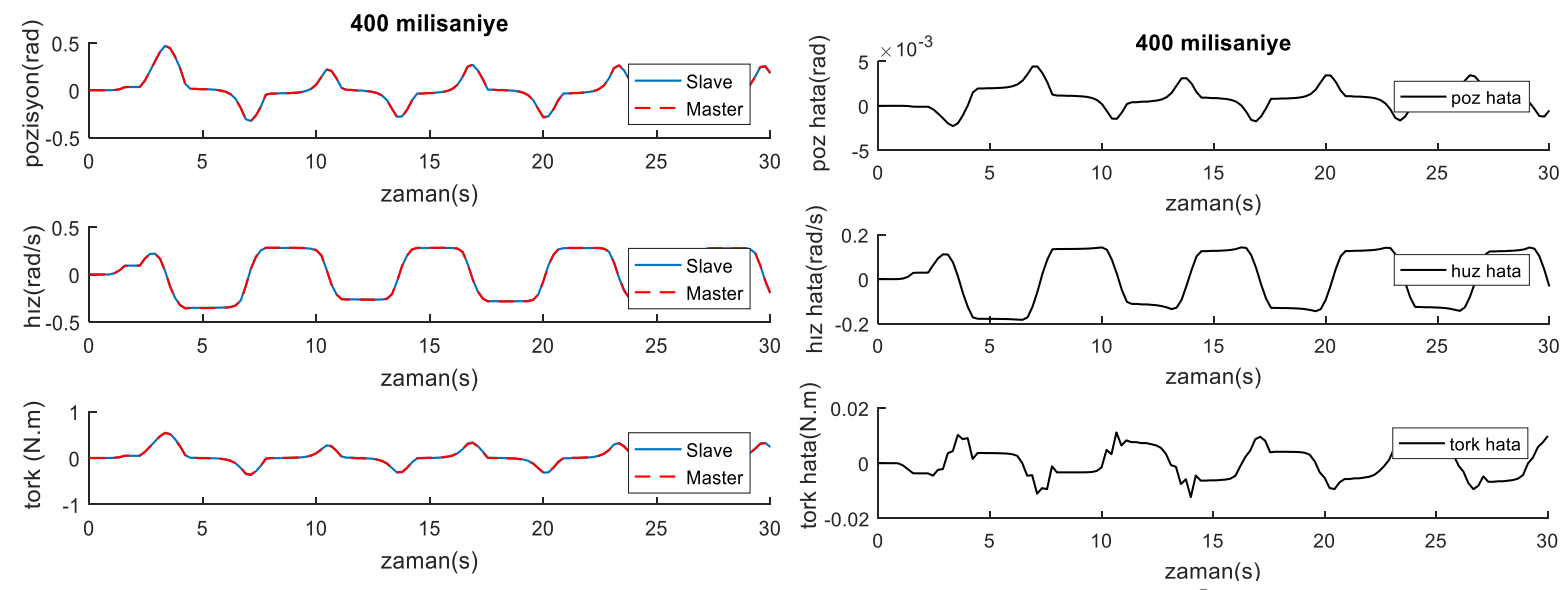

b

Şekil 8. 400 ms zaman gecikmesi varlığında elde edilen robot eklem açısı
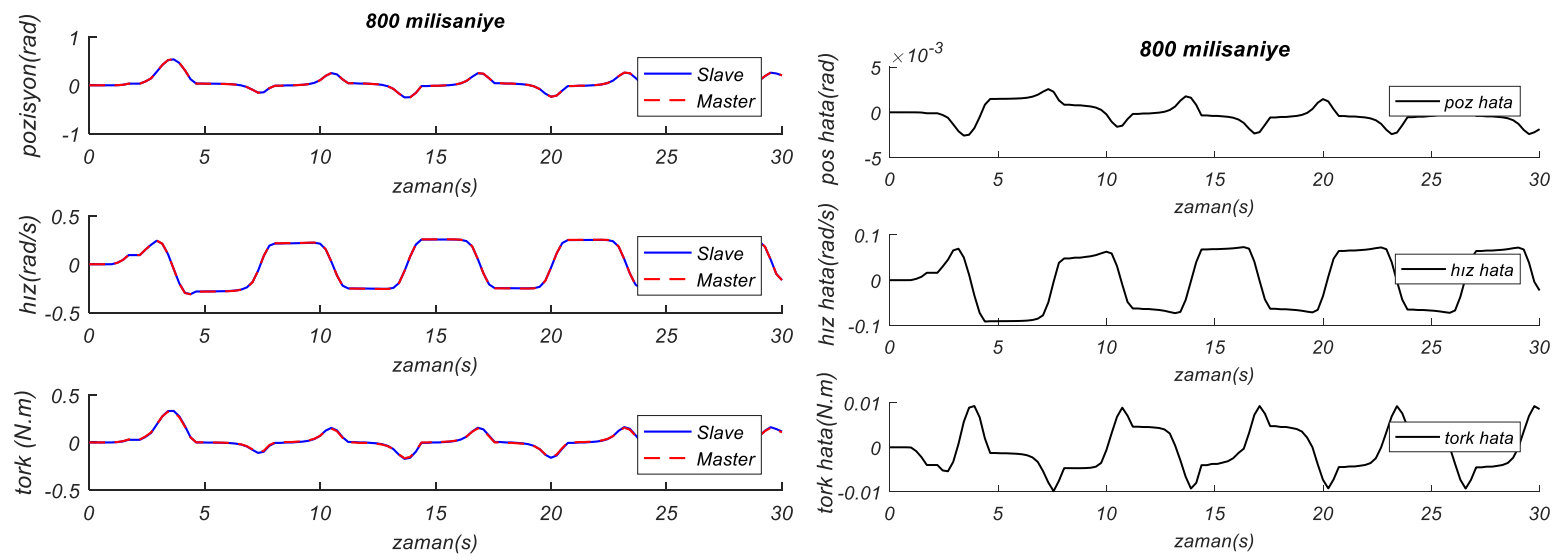

$\mathbf{a}$
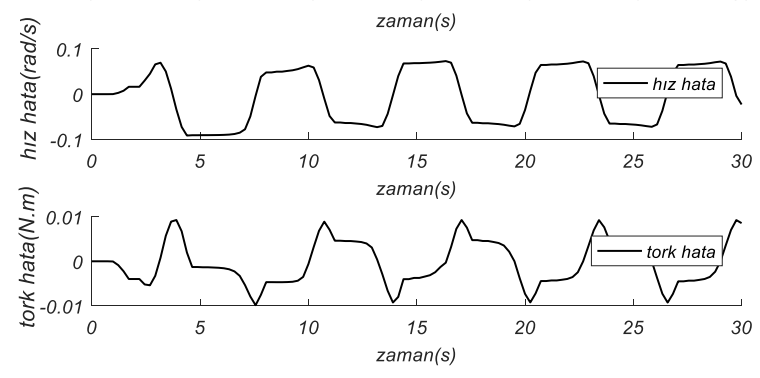

b

Şekil 9. 800 ms zaman gecikmesi varlığında elde edilen robot eklem açısı

$400 \mathrm{~ms}$ sabit zaman gecikmesi varlığında elde edilen grafikler gözlemlendiğinde ana robot tarafindan gönderilen pozisyon değerinin bağımlı robot tarafina iletildiği ve hata değerinin $+5^{*} 10^{-3} \sim-5^{*} 10^{-3}$ değerleri arasında değiştiği görülmüştür. Hız grafiği göz önüne alındığında büyük ölçüde takip ettiği ve hata değerlerinin $+0.2 \sim-0.2$ değerleri arasında değiştiği görülmüştür. Tork grafiği incelendiğinde büyük ölçüde $+0.02 \sim-0.02$ aralığında değiştiği gözlemlenmiştir. $800 \mathrm{~ms}$ sabit zaman gecikmesi varlığında elde edilen grafikler gözlemlendiğinde ana robot tarafindan gönderilen pozisyon değerinin bağımlı robot tarafina iletildiği ve hata değerinin yaklaşık $+5^{*} 10^{-3} \sim-5^{*} 10^{-3}$ değerleri arasında değiştiği görülmüştür. Hız grafiği göz önüne alındığında büyük ölçüde takip ettiği ve hata değerlerinin yaklaşık $+0.1 \sim-0.1$ değerleri arasında değiştiği görülmüştür. Tork grafiği incelendiğinde büyük ölçüde takip ettiği ve hata performansının yaklaşık $+0.01 \sim-0.01$ aralığında değiştiği gözlemlenmiştir. Tablo 1 ve 2'de sırasıyla MAE ve MSE kriterlerine göre verilen hata değerleri gösterilmiştir.

Tablo 1. MAE kriterine göre ile elde edilen hata değerleri

\begin{tabular}{|c|c|c|c|}
\hline $\begin{array}{c}\text { Zaman Gecikmesi } \\
\text { (milisaniye) }\end{array}$ & $\begin{array}{c}\text { Pozisyon } \\
\text { (rad) }\end{array}$ & $\begin{array}{c}\text { Hiz } \\
(\mathbf{r a d} / \mathbf{s})\end{array}$ & $\begin{array}{c}\text { Tork } \\
\text { (N.m) }\end{array}$ \\
\hline 200 & 0.0034 & 0.00545 & 0.0042 \\
\hline 400 & 0.0025 & 0.01077 & 0.0048 \\
\hline 800 & 0.0018 & 0.02027 & 0.0124 \\
\hline
\end{tabular}


Tablo 2. MSE kriterine göre ile elde edilen hata değerleri

\begin{tabular}{|c|c|c|c|}
\hline $\begin{array}{c}\text { Zaman Gecikmesi } \\
\text { (milisaniye) }\end{array}$ & $\begin{array}{c}\text { Pozisyon } \\
\text { (rad) }\end{array}$ & $\begin{array}{c}\text { Hız } \\
\text { (rad/s) }\end{array}$ & $\begin{array}{c}\text { Tork } \\
\text { (N.m) }\end{array}$ \\
\hline 200 & 0.00044 & 0.00036 & 0.0013 \\
\hline 400 & 0.00034 & 0.00139 & 0.0024 \\
\hline 800 & 0.00013 & 0.00507 & 0.0098 \\
\hline
\end{tabular}

Tablo 1'de verilen MAE kriterine göre elde edilen sonuçlara göre 200 milisaniye zaman gecikmesi varlığında pozisyon hata değeri 0.0034 radyan olarak elde edilmiştir. Hiz ve tork hata değerleri ise sirasıyla $0.00545 \mathrm{rad} / \mathrm{s}$ ve 0.0042 N.m olarak elde edilmiştir. 400 milisaniye zaman gecikmesi varlığında pozisyon hata değeri 0.0025 radyan olarak elde edilmiştir. Hız ve tork hata değerleri ise $0.01077 \mathrm{rad} / \mathrm{s}$ ve $0.0048 \mathrm{~N} . \mathrm{m}$ olarak elde edilmiştir. 800 milisaniye zaman gecikmesi varlığında pozisyon hata değeri 0.0018 radyan olarak elde edilmiştir. Hız ve tork hata değerleri ise $0.02027 \mathrm{rad} / \mathrm{s}$ ve 0.0189 N.m olarak elde edilmiştir. Tablo 2'de verilen MSE kriterine göre elde edilen sonuçlara göre 200 milisaniye zaman gecikmesi varlığında pozisyon hata değeri 0.00044 radyan olarak elde edilmiştir. Hız ve tork hata değerleri ise sırasıyla $0.00036 \mathrm{rad} / \mathrm{s}$ ve 0.0013 N.m olarak elde edilmiştir. 400 milisaniye zaman gecikmesi varlığında pozisyon hata değeri 0.00034 radyan olarak elde edilmiştir. Hız ve tork hata değerleri ise $0.00139 \mathrm{rad} / \mathrm{s}$ ve $0.0024 \mathrm{~N}$.m olarak elde edilmiştir. 800 milisaniye zaman gecikmesi varlığında pozisyon hata değeri 0.00013 radyan olarak elde edilmiştir. Hız ve tork hata değerleri ise $0.00507 \mathrm{rad} / \mathrm{s}$ ve 0.0098 N.m olarak elde edilmiştir. 200 milisaniye sabit zaman gecikmesi varlı̆̆ında pozisyon açısı için Tablo 1 ve Tablo 2 karşılaştırılarak incelendiğinde en iyi hata performansı MSE kriterine göre elde edilmiş ve değeri 0.00044 'dır. MAE kriterine göre değeri daha büyük bir değer olan 0.0034 radyan olarak elde edilmiştir. Benzer şekilde hız hata performansı göz önüne alındığında $0.00036 \mathrm{rad} / \mathrm{s}$ olarak MSE kriterine göre elde edilmiştir. MAE kriterine göre değeri daha büyük bir değer olan $0.00545 \mathrm{rad} / \mathrm{s}$ olarak elde edilmiştir. Tork hata performansına bakıldığında 0.0013 N.m değeri MSE kriterine göre elde edilmiştir. MAE kriterine göre değeri daha büyük bir değer olan 0.0042 N.m'dir. 400 milisaniye sabit zaman gecikmesi varlığında pozisyon açısı için Tablo 1 ve Tablo 2 karşılaştırılarak incelendiğinde en iyi hata performansı MSE kriterine göre elde edilmiş ve değeri 0.00034'dür.MAE değeri ise 0.0025 radyan olarak elde edilmiştir. Benzer şekilde hız hata performansı göz önüne alındığında $0.00139 \mathrm{rad} / \mathrm{s}$ olarak MSE kriterine göre elde edilmiştir. MAE kriterine göre değeri daha büyük bir değer olan $0.01077 \mathrm{rad} / \mathrm{s}$ olarak elde edilmiştir. Tork hata performansına bakıldığında 0.0024 N.m değeri MSE kriterine göre elde edilmiştir. MAE kriterine göre değeri daha büyük bir değer olan 0.0048 N.m olarak elde edilmiştir. 800 milisaniye sabit zaman gecikmesi varlığında pozisyon açısı için Tablo 1 ve Tablo 2 karşılaştırılarak incelendiğinde en iyi hata performansı MSE kriterine göre elde edilmiş ve değeri 0.00013 radyandır. MAE kriteri göre değeri daha büyük bir değer olan 0.0018 radyan olarak elde edilmiştir. Benzer şekilde hız hata performansı göz önüne alındığında $0.00507 \mathrm{rad} / \mathrm{s}$ olarak MSE kriterine göre elde edilmiştir. MAE kriterine göre değeri daha büyük bir değer olan $0.02027 \mathrm{rad} / \mathrm{s}$ olarak elde edilmiştir. Tork hata performansına bakıldığında 0.0098 N.m değeri MSE kriterine göre elde edilmiştir. MAE kriterine göre değeri daha büyük bir değer olan 0.00124 N.m olarak elde edilmiştir. Benzetim çalışmaları sonucu farklı sabit zaman gecikmeleri varlığında elde edilen performans sonuçlar şekil ve tablolar verilmiştir. Genel olarak en düşük tork ve hız hatası $200 \mathrm{~ms}$ 'de elde edilmiştir. Ancak en iyi pozisyon hata performans $1800 \mathrm{~ms}$ 'de elde edilmiştir. Elde edilen sonuçlara göre MSE kriteri değerleri genel olarak bu çalışmada iyi performans göstermiştir.

\section{Sonuçlar}

$\mathrm{Bu}$ çalışmada haptik-teleoperasyon sistemlerinin performansı etkileyen en önemli problemlerden biri olan zaman gecikmesi problemi giderilmeye çalışılmış̧ır. Tek serbestlik dereceli robotlardan oluşan haptikteleoperasyon sisteminin sabit zaman gecikmesi varlığında kontrolü gerçekleştirilmiştir.200,400 ve 800 milisaniye sabit zaman gecikmelerinin varlığında sistem kontrol edilmiştir. Dalga değişken yöntemi(Wave Variables Method) kullanılarak sabit zaman gecikmeleri telafi edilmiştir. Elde edilen sonuçlar iki farklı performans kriterleri (MAE ve MSE) kullanılarak elde edilmiş ve tablolar şeklinde verilmiştir. Tüm sonuçlar grafikler ve tablolar şeklinde verilmiştir ve irdelenmiştir. Genel olarak en düşük tork ve hız hatası $200 \mathrm{~ms}$ 'de elde edilmiştir. Ancak en iyi pozisyon hata performans 800 ms' de elde edilmiştir. Elde edilen sonuçlara göre MSE kriteri değerleri genel 
olarak bu çalışmada iyi performans göstermiştir. Benzetim çalışmaları sonucu kabul edilebilir hata performansları elde edilmiştir. İleride yapılacak çalışmalarda laboratuvar ortamında uygulaması gerçekleştirilebilir.

\section{Teşekkür}

Bu çalı̧̧ma Tayfun ABUT 'un doktora tezinden üretilmiştir ve 2211 / C Yurtiçi Öncelikli Doktora Burs Programı kapsamında Türkiye Bilimsel ve Teknolojik Araştırma Kurumu (TÜBİTAK) tarafından desteklenmiştir.

\section{Kaynaklar}

[1] Zilles CB, Salisbury JK. constraint-based god-object method for haptic display. In: Proceedings 1995 ieee/rsj international conference on intelligent robots and systems. Human robot interaction and cooperative robots. IEEE, 1995.146-151.

[2] Abut T, Soyguder S. Interface Design and Performance Analysis for a Haptic Robot. Mus Alparslan Üniversitesi Fen Bilimleri Dergisi, 2018; 6(2):553-560.

[3] Black DG, Hosseinabadi AHH, Salcudean SE. 6-DOF Force Sensing for the Master Tool Manipulator of the da Vinci Surgical System. IEEE Robotics and Automation Letters, 2020; 5(2): 2264-2271.

[4] Abut T, Soyguder S, Haptic industrial robot control and bilateral teleoperation by using a virtual visual interface. 26th Signal Processing and Communications Applications Conference (SIU). IEEE, 2018. p. 1-4.

[5] Lee D, Franch, A, Son HI, Ha C, Bülthoff HH, Giordano PR. Semiautonomous haptic teleoperation control architecture of multiple unmanned aerial vehicles. IEEE/ASME Transactions on Mechatronics, 2013; 18(4):1334-1345.

[6] Ferrell WR. Delayed force feedback. Human factors, 1966; 8(5): 449-455.

[7] Anderson RJ, Spong MW, Bilateral control of teleoperators with time delay. IEEE Transactions on Automatic control, 1989; 34(5):494-501.

[8] Niemeyer G, Slotine JJE. Stable adaptive teleoperation. IEEE Journal of oceanic engineering, 1991; 16(1): 152-162.

[9] Munir S, Book WJ. Internet based teleoperation using wave variables with prediction. In: 2001 IEEE/ASME International Conference on Advanced Intelligent Mechatronics. Proceedings (Cat. No. 01TH8556). IEEE, 2001. p. 43-50.

[10] Chopra N, Spong MW, Ortega R, Barabanov NE On tracking performance in bilateral teleoperation. IEEE Transactions on Robotics, 2006; 22(4):861-866.

[11] Hirche S, Ferre M, Barrio J, Melchiorri C, Buss M. Bilateral control architectures for telerobotics. In: Advances in Telerobotics. Springer, Berlin, Heidelberg, 2007. p. 163-176.

[12] Diolaiti N, Niemeyer G, Tanner NA. Wave haptics: Building stiff controllers from the natural motor dynamics. The International Journal of Robotics Research, 2007; 26(1): 5-21.

[13] Rodriguez-Seda EJ, Lee D, Spong MW. Experimental comparison study of control architectures for bilateral teleoperators. IEEE Transactions on robotics, 2009; 25(6):1304-1318.

[14] Benedetti C, Franchini M, Fiorini P. Stable tracking in variable time-delay teleoperation. In: Proceedings 2001 IEEE/RSJ International Conference on Intelligent Robots and Systems. Expanding the Societal Role of Robotics in the the Next Millennium (Cat. No. 01CH37180). IEEE, 2001. p. 2252-2257.

[15] Aziminejad A, Tavakoli M, Patel RV, Moallem M. Stability and performance in delayed bilateral teleoperation: Theory and experiments. Control Engineering Practice, 2008;16(11): 1329-1343.

[16] Bate L., Cook CD, Li Z. Reducing wave-based teleoperator reflections for unknown environments. IEEE Transactions on Industrial Electronics, 2009:58(2):392-397.

[17] Li H, Kawashima K. Experimental comparison of backdrivability for time-delayed telerobotics. Control Engineering Practice, 2014; 28:90-96.

[18] Soyguder S, Abut T. Haptic industrial robot control with variable time delayed bilateral teleoperation. Industrial Robot: An International Journal, 2016; 43(4): 390-402.

[19] Sun D, Naghdy F, Du H. Wave-variable-based passivity control of four-channel nonlinear bilateral teleoperation system under time delays. IEEE/ASME transactions on mechatronics, 2015; 21(1): 238-253.

[20] Chen Z, Huang F, Sun W, Song W. An improved wave-variable based four-channel control design in bilateral teleoperation system for time-delay compensation. IEEE Access, 2018; 6: 12848-12857.

[21] Guo J, Liu C, Poignet P. A scaled bilateral teleoperation system for robotic-assisted surgery with time delay. Journal of Intelligent \& Robotic Systems, 2019;95(1): 165-192.

[22] Abut T, Soyguder S Zaman Gecikmeli İnsan-Makine Etkileşimli Teleoperasyon Sisteminin Kontrolü. Fırat Üniversitesi Mühendislik Bilimleri Dergisi, 2018; 30(1): 193-202.

[23] Luo J, Liu C, Wang N, Yang C. A wave variable approach with multiple channel architecture for teleoperated system. IEEE Access, 2019; 7: 143912-143920. 